\title{
AÇÃO DO EXTRATO DE Jatropha gossypiifolia L. (PIÃO ROXO) NA CICATRIZAÇÃO DE ANASTOMOSE COLÔNICA: ESTUDO EXPERIMENTAL EM RATOS ${ }^{1}$
}

\author{
Effects of Jatropha gossypiifolia L. (bellyache bush) extract on the healing process of colonic \\ anastomosis: experimental study in rats
}

\begin{abstract}
Santiago Cirilo Nogueira Servin ${ }^{3}$, Orlando Jorge Martins Torres², Jorge Eduardo F. Matias ${ }^{4}$, Miguel Ângelo Agulham ${ }^{4}$, Fábio Augusto de Carvalho ${ }^{5}$, Ricardo Lemos ${ }^{6}$, Emerson Wander Silva Soares ${ }^{6}$, Paulo Roberto Soltoski ${ }^{5}$, Alexandre Coutinho Teixeira de Freitas ${ }^{4}$
\end{abstract}

1. Trabalho realizado no laboratório de pesquisas do centro de Ciências Biológicas e da Saúde da Universidade Federal do Maranhão

2. Professor do Departamento de Cirurgia da Universidade Federal do Maranhão

3. Médico do Hospital da Universidade Federal do Maranhão

4. Professor Doutor em Cirurgia

5. Aluno de Pós-Graduação - Mestrado

6. Aluno de Pós-Graduação - Doutorado

\section{RESUMO}

Introdução: A fitoterapia vem despertando crescente interesse na comunidade científica em relação às suas potenciais propriedades cicatriciais. Poucos são os estudos com metodologia científica existentes na literatura, constituindo-se assim um campo aberto para novas investigações. Objetivos: Analisar a ação da Jatropha gossypiifolia L. (pião roxo) na cicatrização de anastomose colônica em ratos. Métodos: Quarenta ratos Wistar foram submetidos à secção de toda a circunferência do cólon, sendo logo anastomosada com oito pontos separados usando fio monofilamentar de polipropileno 6-0. Aleatoriamente, os animais foram distribuídos em grupo controle (GC), contendo 20 ratos, nos quais foi administrada solução de cloreto de sódio a $0,9 \%$ por via intraperitoneal $(1 \mathrm{ml} / \mathrm{kg}$ ) e grupo Jatropha (GJ), também com 20 nos quais foi administrado o extrato hidroalcoólico de Jatropha gossypiifolia L. por via intraperitoneal ( $1 \mathrm{ml} / \mathrm{kg})$. Cada um dos grupos foi subdividido em dois subgrupos de dez animais de acordo com a data de sacrifício, três e sete dias (GC3/ GC7 e GJ3/GJ7). Após o sacrifício foi retirada parte do cólon compreendendo $1 \mathrm{~cm}$ acima e abaixo da anastomose e submetido ao teste de resistência à insuflação de ar atmosférico. A seguir, foi aberta e retirada uma porção de 1,0 x $0,5 \mathrm{~cm}$ de tamanho colocada em formol a 10\% para análise histológica, na qual foram usadas a coloração de Hematoxilina-Eosina e o Tricrômico de Masson. Resultados: Na avaliação do teste de pressão de ruptura entre os grupos houve significância estatística quando avaliados em relação à data de sacrifício Assim no terceiro dia a média no GC (25,4 mmHg.) e no GJ (76,4 mmHg.) estabeleceu $\mathrm{p}=0.013$, e no sétimo dia a média no GC (187,3 mmHg.) e no GJ (135,1 mmHg.) estabeleceu p $=0.014$. Ao analisar as variáveis microscópicas entre os grupos no $3^{\circ}$ dia, somente não houve diferença significativa nas variáveis edema e polimorfonucleares. Já no $7^{\circ}$ dia todas as variáveis analisadas apresentaram diferença significativa. Conclusões: Na resistência mecânica pôde-se concluir que houve influência positiva da jatropha na aquisição de força na anastomose no terceiro dia. Entretanto, no sétimo dia o GC suplantou siginificativamente a pressão de ruptura obtida no GJ, sugerindo diminuição da ação da Jatropha em fase mais avançada da cicatrização. Na avaliação histológica pôde-se verificar avanço no processo inflamatório agudo no GJ3 em relação ao GC3, mantendo-se ainda mais intenso na fase crônica quando comparados os dois grupos no sétimo dia.

Descritores: Cicatrização de Feridas. Plantas Medicinais. Jatropha gossypiifolia L. Anastomose Cirúrgica. Ratos.

\footnotetext{
ABSTRACT

Introduction: Phytotherapy has been drawing interest from the scientific community regarding its potential wound healing properties. There are few studies available that present a correct scientific methodology and, therefore, phytotherapy remains an open field for further research. Purpose: To evaluate the effects of Jatropha gossypiifolia L. (bellyache bush) on the healing of colonic anastomosis in rats. Methods: Forty Wistar rats were subjected to a complete section of the colon, that was soon sutured with eight separate stitches using monofilament polipropilene 6-0. Randomly, the animals were divided into control group (CG), with 20 rats, which were injected with $0.9 \%$ sodium chloride solution intraperitoneally $(1 \mathrm{~mL} / \mathrm{kg})$ and Jatropha group (JG), also with 20 rats, which were injected with Jatropha gossypiifolia L. alcoholic extract intraperitoneally $(1 \mathrm{~mL} / \mathrm{kg})$. Each of the groups was subdivided into two subgroups of ten rats, according to the sacrifice date, third and seventh days (CG3/ CG7 and JG3/ JG7). After sacrifice, the segment of the colon containing $1 \mathrm{~cm}$ proximal and distal to the site of anastomosis was removed and subjected to the pressure test with air insuflation. This segment
} 
was then opened and a $1.0 \times 0.5 \mathrm{~cm}$ part was removed and placed under $10 \%$ formaldehyde for histological analysis with hematoxylin-eosin and Masson's trichrome stainings. Results: The evaluation of the pressure rupture test demonstrated statistical significance regarding the sacrifice date. On the third day, the average pressure of the $\mathrm{CG}(25,4 \mathrm{mmHg})$ and the JG $(76,4 \mathrm{mHg})$ revealed $\mathrm{p}=0.013$, and on the seventh day, the average pressure of the CG $(187,3 \mathrm{mmHg}$.) and the JG $(135,1 \mathrm{mmHg}$.) revealed $\mathrm{p}=0.014$. When assessing the microscopic variables among the groups of the 3rd day, only the variables edema and polymorphonuclear cells did not show statistical differences. On the 7th day, all of the variables assessed demonstrated significant differences. Conclusions: Regarding mechanical resistance, there was a difference in resistance between the JG3 and the CG3, and a shift of resistance when comparing the JG7 and CG7, which suggests a weakening of the Jatropha effect at a later stage of healing. The histological evaluation revealed an improvement of the acute inflammatory process in the JG3 when compared to the CG3, which was even more intense during the chronic stage, when the two groups are compared on the seventh day. The histological study of the inflammatory process, in general, showed a favorable effect to the Jatropha group compared to the control group.

Key Words: Wound Healing. Plants, Medicinal. Jatropha gossypiifolia L. Anastomosis, Surgical. Rats.

\section{Introdução}

A cicatrização das feridas apresenta fases bem estabelecidas e conhecidas como a fase inflamatória ou exsudativa, a proliferativa ou regenerativa e a de maturação, remodelação ou reparativa ${ }^{1,2,3}$. É evento que depende de vários fatores, sistêmicos e locais, tais como distúrbio nutricional, hipóxia tecidual, insuficiência renal, deficiência de zinco, uso de antiinflamatórios, imunossupressão, anemia, diabetes, idade avançada e infecção, que agem retardando ou bloqueando o processo cicatricial ${ }^{1,2}$.

O estudo da cicatrização no intestino de modelos animais ajudou a melhorar os conhecimentos, métodos e materiais usados nas suturas, e conseqüentemente a cicatrização do trato gastrintestinal. Hoje se sabe que a cicatrização do trato intestinal é em parte diferente da cicatrização cutânea e a deiscência é a mais grave complicação na anastomose colônica, com elevada morbidade e mortalidade ${ }^{4,5}$. Muitos são os fatores sistêmicos e locais que podem levar ao insucesso no processo cicatricial nas anastomoses intestinais, entre eles o estado nutricional do paciente, o preparo préoperatório e a técnica cirúrgica ${ }^{6,7}$.

A Jatropha gossypiifolia $L$. ou pião roxo é planta cosmopolita muito conhecida na América Latina, Caribe, Índia e na África Ocidental onde é usada popularmente, pela sua capacidade antiinflamatória, como planta medicinal para várias doenças. Em algumas regiões do Brasil ela é usada de forma ritualística por ser considerada venenosa. Pertence à família Euphorbiaceae, do gênero Jatropha e da espécie Jatropha gossypiifolia L. A este gênero pertencem outras espécies como a Jatropha curcus, Jatropha podagrica, Jatropha elliptica, Jatropha multifida e a Jatropha glandulifera, também usadas popularmente ${ }^{6,7,8,9}$. Pretende-se neste estudo analisar a ação da Jatropha gossypiifolia L. (pião roxo) na cicatrização de anastomose colônica em ratos, através da resistência mecânica por pressão de ruptura com insuflação de ar atmosférico e o estudo histológico do processo inflamatório.

\section{Métodos}

Amostra

Foram utilizados 40 ratos (Rattus norvegicus albinus,
Rodentia mammalia), machos, da linhagem Wistar, pesando entre 110 e 180 gramas, ambientados e aclimatados por cinco dias para adaptação sob temperatura ambiente e ciclo $\mathrm{dia} /$ noite, em grupos de cinco animais por gaiola de $0,15 \mathrm{~m}^{2}$, forradas com maravalha, recebendo ração padrão para ratos (PURINA ${ }^{\circledR}$ - Labina) e água ad libitum.

Preparo do extrato hidroalcoólico da Jatropha gossypiifolia $L$.

A Jatropha gossypiifolia L. (pião roxo) foi coletada de uma planta desenvolvida de forma selvagem na Ilha de São Luis. As partes aéreas (folhas, galhos e flores) foram retiradas e a partir deste material preparou-se o extrato hidroalcoólico para uso no experimento. Após a coleta, este material foi transferido para o Laboratório de Produtos Naturais (LPN) do Departamento de Química da UFMA.

A parte aérea da planta foi deixada a secar em temperatura ambiente por cinco dias, a seguir foi colocada em estufa de secagem para retirada da umidade na temperatura de $45-50^{\circ} \mathrm{C}$ por 24 horas. $\mathrm{O}$ material seco foi submetido à moagem em moínho elétrico, obtendo-se um pó de coloração esverdeada na quantidade de dois quilogramas. Ele foi submetido a diluições sucessivas com álcool a 70\% e água destilada, agitada a cada duas horas por um período de 12 horas. A quantidade resultante, após filtragem em funil de vidro através de algodão, foi de $5400 \mathrm{ml}$, constituindo-se assim o extrato bruto da Jatropha gossypiifolia L. Por meio de um evaporador rotativo na temperatura de $60^{\circ} \mathrm{C}$ para eliminação do solvente, foi obtida uma pasta, a partir da qual foi preparado o extrato final, acondicionado em frasco de vidro e colocado em refrigerador em temperatura constante de $10^{\circ} \mathrm{C}$.

\section{Etapas experimentais}

\section{Pré-operatório}

Após período de aclimatação de cinco dias com ração padrão e água ad libitum, os animais eram submetidos a jejum pré-operatório de 12 horas, pesados e logo após receberam indução anestésica inalatória em campânula de vidro contendo algodão embebido em éter sulfúrico comercial a $50 \%$ em sistema fechado. Eles eram imobilizados com fita 
adesiva em prancha de madeira. Procedia-se a epilação da região abdominal caudal de cada animal, seguida de antisepsia da região com PVPI - polivinil-pirrolidona-iodo e colocação de campo fenestrado para exposição do abdome. Não foram usados antibióticos nem preparo pré-operatório do cólon.

\section{Técnica operatória}

Procedeu-se incisão mediana de aproximadamente quatro centímetros, dois centímetros abaixo do processo xifóide, abrangendo pele, plano músculo-aponeurótico e peritônio, expondo as vísceras abdominais, identificando e exteriorizando o cólon ascendente. Ele foi seccionado em toda sua circunferência a dois centímetros distal à reflexão peritoneal, sendo em seguida anastomosado com inversão da mucosa com oito pontos separados em plano único (pontos de Lambert), usando fio monofilamentar de polipropileno 6-0 (Figura 1). Após este procedimento comum, os animais foram distribuídos aleatoriamente em dois grupos contendo 20 ratos cada, sendo o Grupo Controle (GC) o que recebeu injeção intraperitoneal (espaço sub-hepático direito) de solução de cloreto de sódio a $0,9 \%$ na quantidade de $1 \mathrm{ml} / \mathrm{kg}$ de peso corpóreo do animal. O Grupo Jatropha
(GJ), recebeu injeção intraperitoneal (espaço sub-hepático direito) de extrato hidroalcoólico de Jatropha gossypiifolia $L$. na quantidade de $1 \mathrm{ml} / \mathrm{kg}$ de peso corpóreo do animal. A síntese da parede abdominal foi feita em dois planos com fio de náilon 5-0 em sutura contínua acometendo o plano músculo-aponeurótico e a pele. Após o procedimento, a ferida operatória foi limpa com solução de cloreto de sódio a $0,9 \%$. Cada grupo foi dividido em dois subgrupos contendo 10 animais cada, definidos como Grupo J3, Grupo J7, Grupo C3 e Grupo C7, conforme data de sacrifício dos animais no terceiro e sétimo dias de pós-operatório. Foram avaliados diariamente, registrando-se o peso, as condições comportamentais e o aspecto da ferida operatória em ficha protocolo individual.

\section{Coleta de dados}

A ferida operatória foi examinada e em seguida, a cavidade abdominal foi aberta mediante duas incisões transversais acima e abaixo da incisão da parede, e uma incisão longitudinal lateral esquerda unindo as incisões transversas, de forma a expor a cavidade peritoneal. Foi realizado o inventário e anotados os achados intraperitoneais referentes à presença de infecção, aderências, fístulas e deiscência de

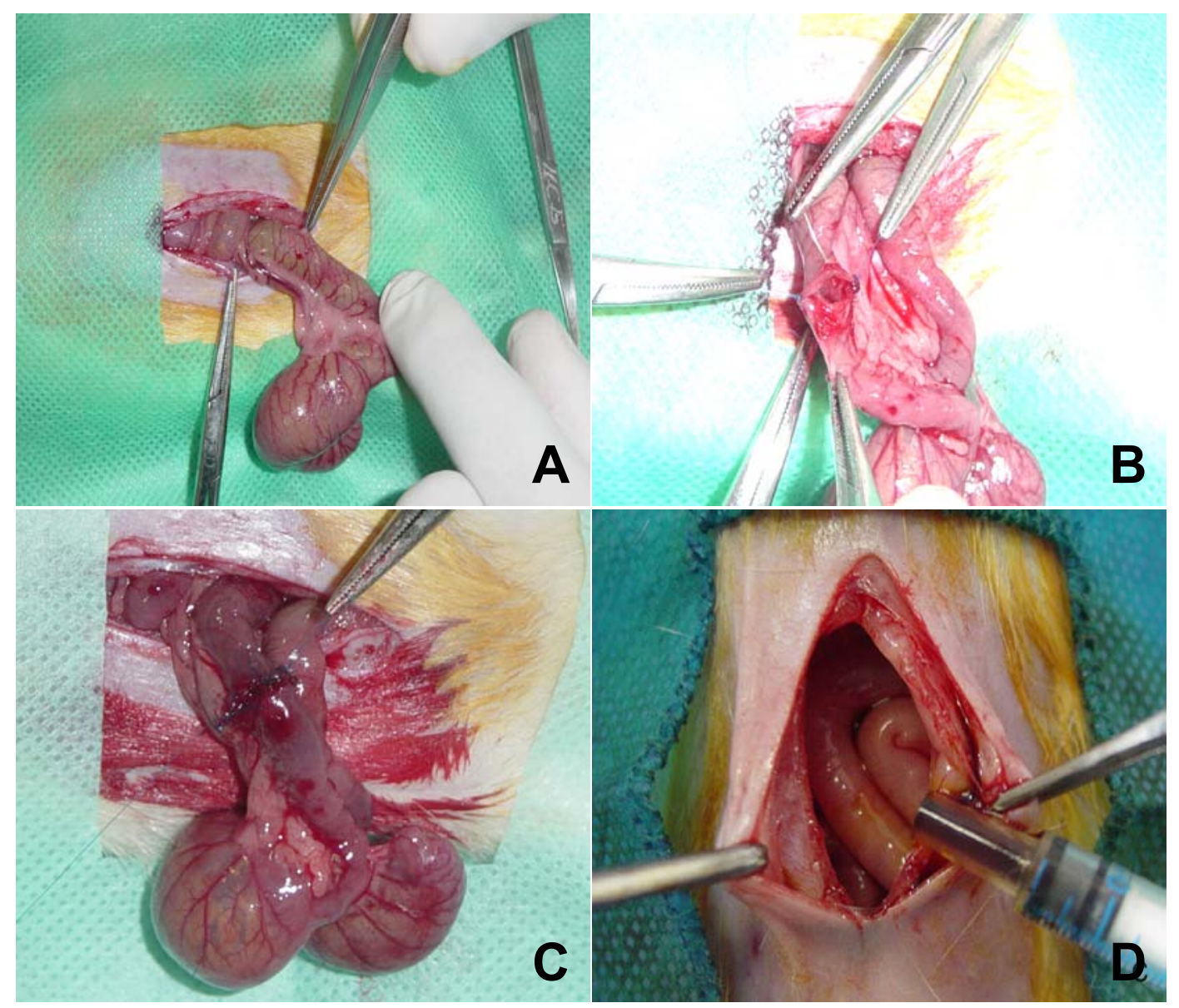

FIGURA 1 - Técnica Operatória: A - Exposição do segmento colônico, B - Colotomia e início da anastomose, C - Anastomose completa, D - Aplicação intraperitoneal do fitoterápico. 
anastomose. A peça foi retirada compreendendo $1 \mathrm{~cm}$ distal $\mathrm{e}$ $1 \mathrm{~cm}$ proximal à anastomose com preservação das aderências, quando presentes. Após a retirada, o segmento foi limpo com solução de cloreto de sódio a $0,9 \%$ e submetido ao teste de resistência à insuflação de ar.

\section{Teste de resistência à insuflação de ar atmosférico}

Consistiu em: a) preparo da peca cirúrgica, mantendo-se as aderências; b) apreensão do segmento distal com pinça hemostática; c) introdução de sonda de silicone $\mathrm{n}^{\circ} 6$ no segmento proximal por $0,5 \mathrm{~cm}$ e fixação dela a este segmento com fio de algodão 2-0; d) conexão da sonda ao manômetro $\left(\mathrm{POLZIN}^{\circledR}\right)$, que foi regulado para insuflação gradativa de ar ambiente; e) submersão da peça em recipiente de vidro contendo água; f) insuflação gradativa de ar ambiente a velocidade de $0,1 \mathrm{~mL} / \mathrm{s}$ até a ocorrência de liberação de bolhas de ar, caracterizando o momento da ruptura da peça, sendo registrado o local da ruptura e a pressão aferida pelo manômetro ${ }^{7}$.

\section{Análise histológica}

O segmento ressecado foi aberto na sua borda antimesentérica, lavado com solução de cloreto de sódio a $0,9 \%$, seccionado em $1,0 \times 0,5 \mathrm{~cm}$ de tamanho, mantendo sempre a anastomose no centro, a face interna da linha de sutura ficou voltada para cima fixada em placa de isopor de $2 \mathrm{~cm}^{2}$ por meio de alfinetes. Em seguida foi colocada em formol a $10 \%$ por $48 \mathrm{~h}$. O preparo histológico da peça cirúrgica obedeceu as seguintes etapas: a) retirada do excesso de formol do tecido em água corrente por 15 minutos; b) desidratação do tecido pelo processo histotécnico com concentrações progressivas de álcool etílico a 70, 80 e 90\%; c) diafanização em xilol; d) impregnação do tecido em parafina liquefeita; e) inclusão com formação dos blocos de parafina.

As peças contidas nos blocos de parafina foram cortadas com micrótomo, ajustados para espessura de $5 \mu \mathrm{m}$, sendo em seguida colocado em banho-maria à temperatura de $45^{\circ} \mathrm{C}$, preparadas em lâminas untadas com albumina de Meyer e secadas em estufa por 24 horas. As lâminas foram coradas pela Hematoxilina-Eosina (HE) e Tricrômico de Masson (TM).

\section{Avaliação microscópica}

As lâminas foram analisadas por um único examinador, utilizando microscópio óptico com ocular 10x e objetivas de 4x, 10x e 40x. A análise histológica obedeceu aos seguintes critérios: a) avaliação do acometimento tecidual pelo processo inflamatório quanto à presença de infiltrado no que diz respeito à intensidade, modo de distribuição no interstício e quanto ao tipo de célula presente; b) avaliação do grau e da distribuição da fibrose intersticial; c) avaliação do grau e da distribuição das fibras colágenas pela coloração de TM.

As áreas de anastomose que foram avaliadas pela coloração de $\mathrm{HE}$, assim como os tipos celulares identificados foram classificados em ausentes, discretos, moderados ou acentuados. Na fase aguda caracterizada pela presença de congestão, edemas e polimorfonucleares foram atribuídos sinais negativos (-) e a fase crônica caracterizada por mononucleares, proliferação fibroblástica (fibrose) e angiogênese foram atribuídos sinais positivos $(+)$. Quando ausente, foi considerado zero (0). A colagenização corada pelo TM foi avaliada da seguinte maneira: a presença do colágeno foi graduada em ausente $(0)$, discreto $(+1)$, moderado $(+2)$ e acentuado $(+3)$. Após a análise microscópica destes fatores e a soma dos valores correspondentes a HE, foram classificados os grupos e subgrupos de acordo com a fase de cicatrização.

\section{Análise estatística}

Os dados foram analisados utilizando-se o programa Statistica for Windows 5.1. A variável numérica Tensão $(\mathrm{mmHg})$ foi avaliada pelo teste $\mathrm{t}$ de Student. As variáveis da avaliação microscópica e macroscópica foram analisadas pelo teste não-paramétrico de Mann-Whitney. Além da análise intergrupo $(\mathrm{C} \times \mathrm{J})$ foi feita a análise intra-grupo. $\mathrm{O}$ nível de significância (a) utilizado para se rejeitar a hipótese da nulidade foi de $5 \%(\mathrm{p}<0,05)$.

\section{Resultados}

\section{Avaliação macroscópica}

A ferida operatória apresentou deiscência parcial em um animal do GC3. No grupo GJ3 houve um abscesso ao nível da anastomose em um animal e uma fístula da anastomose colônica em outro. Nos animais restantes não houve alterações e a cicatrização foi considerada boa.

Avaliação do teste de resistência à insuflação de ar atmosférico

Em um rato do GJ3 ela não pôde ser feita por ter apresentado uma fístula ao nível da anastomose. As anastomoses dos demais animais foram avaliadas sem nenhuma intercorrência (Tabela 1).

TABELA 1 - médias e desvio padrão da pressão de ruptura entre os grupos controle e Jatropha no $3^{\circ}$ e $7^{\circ}$ dias pósoperatórios.

\begin{tabular}{|c|c|c|c|}
\hline${ }_{\text {Tempo }}^{\text {Grupo }}$ & GC & GJ & p \\
\hline 3 Dias & $\begin{array}{c}25,4 \pm \\
14,1 \mathrm{mmHg}\end{array}$ & $\begin{array}{c}76,4 \pm \\
56,1 \mathrm{mmHg}\end{array}$ & $* 0.013$ \\
\hline 7 Dias & $\begin{array}{c}187,3 \pm \\
39,5 \mathrm{mmHg}\end{array}$ & $\begin{array}{c}135,1 \pm \\
45,7 \mathrm{mmHg}\end{array}$ & $* 0.014$ \\
\hline
\end{tabular}

\section{Avaliação microscópica}

A inflamação aguda no GC3 e no GJ3 não apresentou diferença significativa na variável edema $(p=0,307)$ e nos polimorfonucleares $(\mathrm{PMN})(\mathrm{p}=0,226)$ (Tabela 2 - Figuras 2 e 3$)$. 
TABELA 2 - Análise das variáveis microscópicas dos grupos controle e Jatropha no $3^{\circ}$ dia pós-operatório. Teste U de Mann-Whitney (Análise intergrupo).

\begin{tabular}{lcccc}
\hline Tempo & Grupo & JATROPHA & u & p \\
\hline Congestão & $-1,5$ & $-0,5$ & 12,5 & $* 0,0046$ \\
Edema & -2 & $-1,5$ & 36,5 & 0,3075 \\
Polimorfonucleares & -2 & -1 & 34 & 0,2265 \\
Mononucleares & 0 & 2 & 4 & $* 0,0005$ \\
Prol. fibroblástica & 0 & 2 & 0 & $* 0,0002$ \\
Angiogênese & 0 & 1 & 20 & 0,0233 \\
Colagenização & 0 & 1 & 5 & $* 0,0007$ \\
Inflamação & $\mathrm{A}$ & $\mathrm{B}, \mathrm{C}$ & 10 & $* 0,0025$ \\
\hline
\end{tabular}

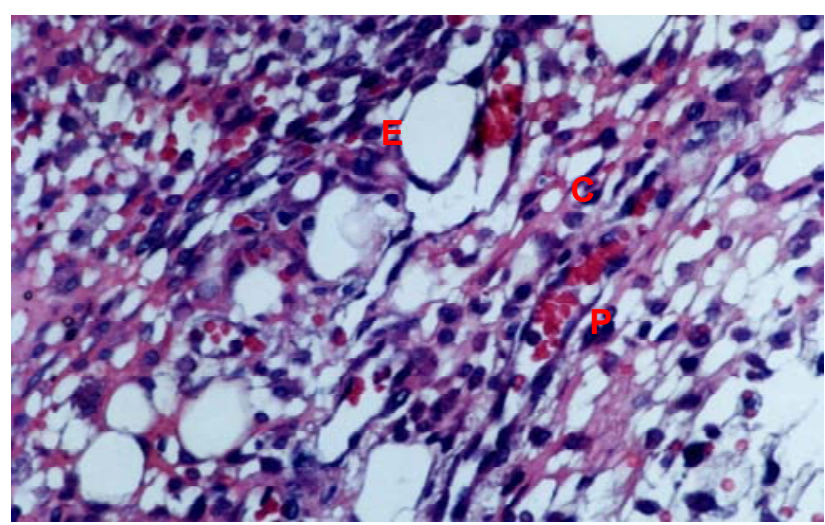

FIGURA 2 - Fotomicrografia da parede colônica de rato do Grupo GC3. Observa-se inflamação aguda com congestão (C), edema (E) e polimorfonucleares (P).Coloração HE 400X.

A inflamação crônica no $7^{\circ}$ dia apresentou todas as variáveis com diferença significativa (Tabela 3 - Figuras 4 e 5).

\section{Discussão}

O pião roxo ou pinhão roxo, como é conhecida a Jatropha gossypiifolia L. no Brasil, tem sido usado na medicina popular para diferentes fins terapêuticos, como reumatismo, úlceras, hidropsias, hipertensão, cicatrização de feridas e purgativo $^{10,11,12}$. O diterpene macrocíclico Jatrophone foi isolado da raiz da planta. e identificado como um inibidor

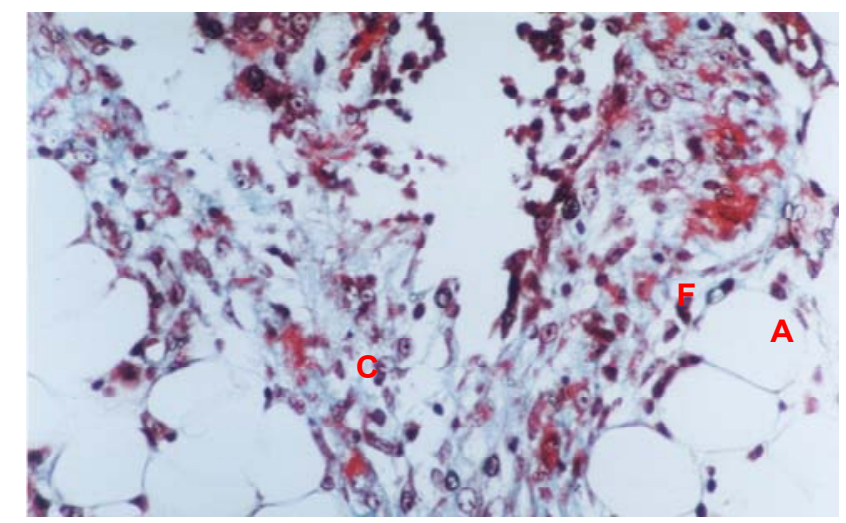

FIGURA 3 - Fotomicrografia da parede colônica de rato do Grupo GJ3. Observa-se inflamação aguda com congestão (C), edema (E) e polimorfonucleares (P).Coloração HE 400X.

do crescimento tumoral ${ }^{11,12,13}$. Alguns estudos avaliaram a ação da Jatropha gossypiifolia L. na contração da musculatura lisa e sua capacidade antihipertensiva, enquanto que outros procuram analisar a sua ação na reatividade vascular na artéria mesentérica de ratos. Sugere-se nestes estudos que o extrato da planta influencia a mobilização do cálcio intracelular, promovendo efeito hipotensor por relaxamento vascular.

O efeito do extrato da Jatropha gossypiifolia L. na cicatrização ainda não foi demonstrado cientificamente, apesar de ser usado na medicina popular como cicatrizante há longo tempo. Este fato leva à pertinência deste estudo, e

TABELA 3 - Análise das variáveis microscópicas dos grupos controle e Jatropha no $7^{\circ}$ dia do pos-operatório. Teste U de Mann-Whitney (Análise intergrupo)

\begin{tabular}{lcccc}
\hline Tempo & GONTROLE & JATROPHA & u & p \\
\hline Congestão & -1 & 0 & 5 & $* 0,0007$ \\
Edema & -2 & 0 & 4 & $* 0,0005$ \\
Polimorfonucleares & -2 & -1 & 15,5 & $* 0,0091$ \\
Mononucleares & 1 & 3 & 8 & $* 0.0015$ \\
Prol. fibroblástica & 0,5 & 3 & 8 & $* 0,0015$ \\
Angiogênese & 0 & 1 & 21,5 & $* 0,0312$ \\
Colagenização & 0 & 2 & 0 & $* 0,0002$ \\
Inflamação & $\mathrm{A}$ & $\mathrm{C}$ & 5 & $* 0,0007$ \\
\hline
\end{tabular}




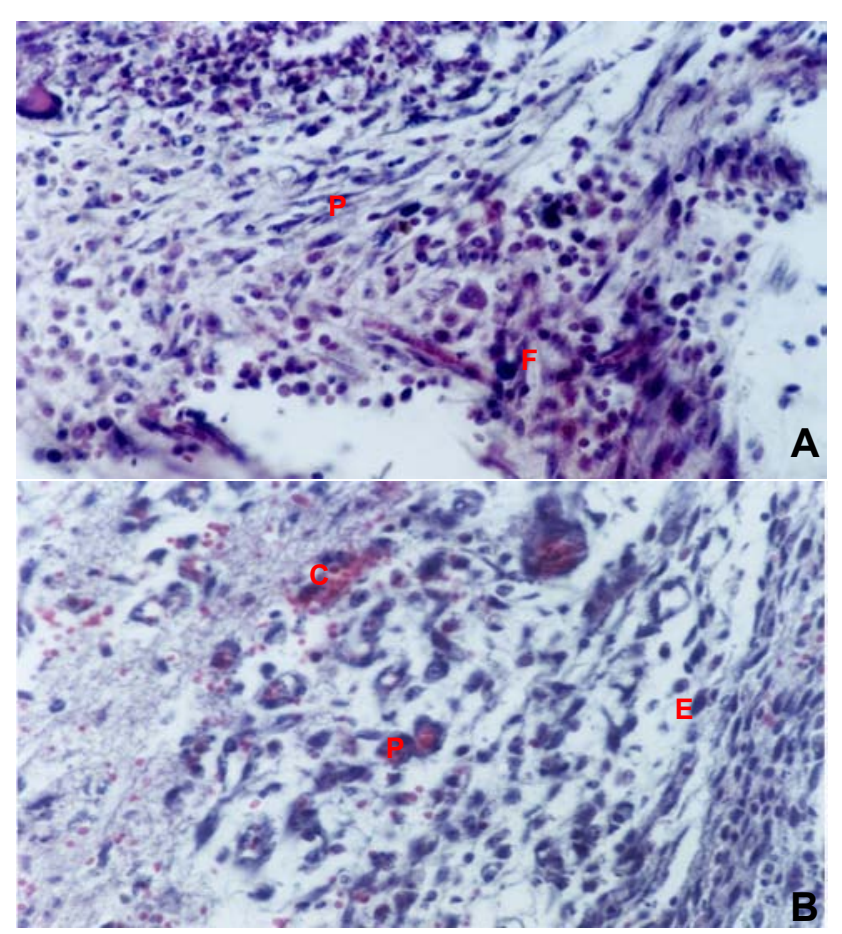

FIGURA 4 - Fotomicrografias do cólon de rato GC7 corado pela técnica hematoxilina - eosina. (A) e tricrômico de masson (B). Em A observa-se inflamação subaguda com polimorfonucleares $(\mathrm{P})$ e proliferação fibroblástica $(\mathrm{F})$; em $\mathrm{B}$ inflamação subaguda com congestão (C), edema (E) e polimorfonucleares (P).

ao modelo experimental aqui utilizado ${ }^{9,10,11,12}$

A anastomose colônica término-terminal foi executada a $2 \mathrm{~cm}$ da reflexão intestinal em plano único e com oito pontos separados, por ser esta técnica habitualmente utilizada na literatura, de fácil execução e segura. O fio de polipropileno 6-0 foi resistente na confecção da anastomose e apresentou pouca reação inflamatória e por estes motivos ele é recomendado freqüentemente em estudos semelhantes ${ }^{12,13,14}$.

O terceiro dia de avaliação é de importância, pois além de um processo inflamatório intenso em nível tecidual neste dia, as anastomoses intestinais nos primeiros três dias de pós-operatório estão com sua força original diminuída e a pressão de ruptura é menor neste período de pós-operatório e vão aumentando gradativamente nos dias subseqüentes. É em torno do sétimo dia que nos humanos ocorrem as complicações referentes às anastomoses intestinais, como extravasamentos, fístulas e deiscências. Por este motivo esta data foi escolhida para avaliação da força tensil ${ }^{11,14,15}$.

A sutura da parede abdominal foi avaliada diariamente. Três animais apresentaram deiscência da sutura da parede abdominal e um infecção da parede abdominal, mas sem alterações da anastomose. Vários graus de aderências foram vistos, sendo que o índice de aderências cresceu com o aumento do tempo de pós-operatório. Estes fatos já foram também reconhecidos por outros autores, contudo eles não interferiram com as anastomoses que puderam ser analisadas com isenção de intercorrências ${ }^{14}$.

Os principais parâmetros para a avaliação das anasto-

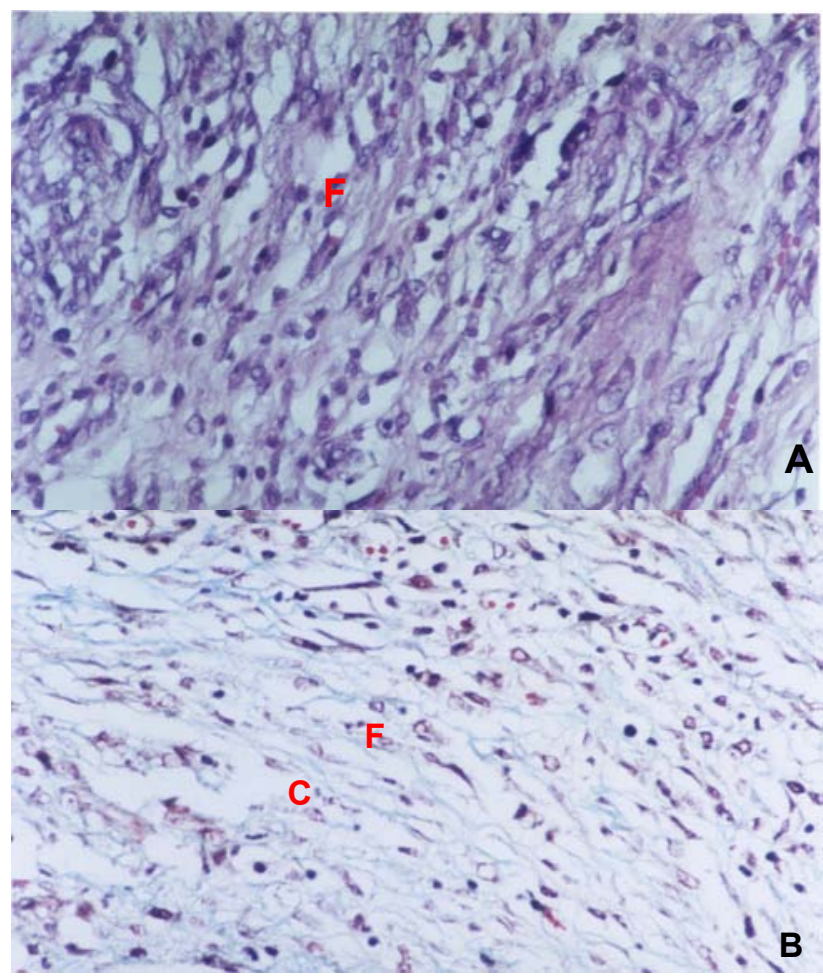

FIGURA 5 - Fotomicrografias do cólon de rato GJ 7 corado pela técnica de hematoxilina - eosina (A) e tricrômico de masson (B). Em A observa-se inflamação crônica com fibroblastos (F); em B inflamação crônica com fibroblastos (F) e colágeno (C).

moses são os histológicos e mecânicos.

Os parâmetros histológicos são muito úteis na descrição do processo e do resultado cicatricial. Eles são precisos e quantificáveis com relativa facilidade e por isto foram escolhidos para avaliar os resultados deste estudo e muito utilizados na literatura. Através deles pode-se analisar a reação inflamatória tanto aguda como crônica e comparar com controles o benefício do objetivo da pesquisa. A força da anastomose pode ser aferida pela concentração e conteúdo do colágeno nela existente. A base de sustentação da forca mecânica na maioria dos tecidos é dependente da presença do colágeno, sendo ele de importância no processo de reparação das feridas. No trato gastrintestinal, ele está localizado principalmente na submucosa. Para que se mantenha a resistência mecânica da parede intestinal é necessário que ocorra um equilíbrio no processo de lise e de síntese do colágeno, fato este que ocorre na parede do intestino normal $^{7,15,16,17}$ e que pôde ser demonstrado no estudo aqui apresentado na avaliação histológica.

Os parâmetros mecânicos são empregados na avaliação da resistência à pressão intraluminal. São também muito bons por poder demonstrar claramente o ponto de ruptura e o momento em que ela ocorre. Existem vários instrumentos que o executam. O aqui utilizado foi simples de fácil manuseio e por isso é recomendável para pesquisa em animais de pequeno porte. Esta também é opinião emitida por outros autores que o manusearam ${ }^{6,10}$.

Qualquer procedimento sobre o trato gastrintestinal leva 
a influxo de células inflamatórias, como monócitos, macrófagos e fibroblastos, no local da anastomose, formando tecido de granulação, e levando a acúmulo de colágeno. As células inflamatórias, na fase inicial da cicatrização, estão em grande quantidade e o processo de cicatrização necessita destes componentes da matriz extracelular na área da anastomose, para facilitar a deposição do colágeno. A síntese máxima de colágeno ocorre na primeira semana de pós-operatório, ganhando força até o sétimo dia; assim a colagenização nos primeiros dias se caracteriza por lise de colágeno maduro mantendo-se maior do que a síntese dele, o que leva a perda da força tênsil da anastomose. Após o sétimo dia há aumento da síntese fortalecendo a rede de colágeno. O balanço entre o processo de lise e síntese é fundamental para restabelecer a força da anastomose, assim pode-se notar que o colágeno é fundamental na sustentação da anastomose, sendo importante seu estudo na avaliação de anastomoses intestinais. Coradas pela técnica de hematoxilina-eosina, as lâminas deste estudo foram avaliadas por parâmetros histológicos clássicos; para a fase aguda, a congestão, edema e presença polimorfonucleares e para a inflamatória avançada, com a quantificação de mononucleares, proliferação fibroblástica e angiogênese, classificadas de maneira já bem aceita e relatada na literatura ${ }^{11,12,15,17,18,19}$.

Neste estudo, os GC3 e GJ3 não apresentaram diferença significativa nas variáveis edema $(\mathrm{p}=0.3075)$ e polimorfonucleares $(p=0,2265)$; em todas as outras variáveis houve diferença significativa. A inflamação apresentou-se moderada e acentuada com diferença significativa $(p=0,0025)$ nestes grupos, assim como a colagenização que também se apresentou com diferença significativa $(p=0,0007)$. Os GC7 e GJ7 apresentaram diferença significativa para todas as variáveis. Assim constata-se que os valores das variáveis entre os grupos do mesmo dia (GC3 e GJ3/ GC7 e GJ7) apresentavam grandes diferenças, mas, se comparar-se os valores dos mesmos grupos de dias diferentes (GC3 e GC7/ GJ3 e GJ7), não se encontra diferença entre os valores. Os GJ apresentam valores nas variáveis bem mais elevados que os GC, sugerindo que há algum estímulo celular por parte da Jatropha durante o processo de cicatrização.

Vários autores apresentam diferentes meios para a medida da pressão de ruptura por insuflação de ar, variando desde o uso de solução salina ou ar para estabelecer pressão na luz intestinal até o uso de manômetros digitais ou manuais para a aferição desta. Manifestações clínicas de insuficiência anastomótica ocorrem durante a primeira semana de pósoperatório, sugerindo que a aferição da pressão de ruptura deve ser nela realizada para poder ser comparada com a realizada em humanos. A pressão de ruptura é significativamente menor nestes primeiros dias de pós-operatório em relação ao sétimo dia, porque na fase inicial a resistência da anastomose é mais dependente das suturas, e na fase tardia mais dependente da reparação tecidual e a deposição de colágeno ${ }^{5,11,15}$.

Nesta pesquisa, as aderências não foram retiradas na tentativa de diminuir a manipulação sobre a anastomose, o que poderia influenciar os resultados e porque, inicialmente, as aderências fornecem oxigênio e nutrientes para a área de reparo através de neovascularização e pelo efeito mecânico de selar as falhas da anastomose $e^{7,8,17}$.

Observa-se neste estudo que a pressão de ruptura no teste de resistência à insuflação de ar foi de $25,4 \mathrm{mmHg}$ no GC3 e $76,4 \mathrm{mmHg}$ no GJ3, com média de $50,99 \mathrm{mmHg}$. No $7^{\circ}$ dia as pressões foram de $187,3 \mathrm{mmHg}$ no $\mathrm{GC}$ e $135,1 \mathrm{mmHg}$ no GJ, com média de $161,20 \mathrm{mmHg}$, estabelecendo $\mathrm{p}=0,000$ estatisticamente significativo para estas duas médias. Ao comparar-se os GC3 $(25,4 \mathrm{mmHg})$ e GC7 $(187,3 \mathrm{mmHg})$, com média de $106,35 \mathrm{mmHg}$, e os GJ3 $(76,4 \mathrm{mmHg})$ e GJ7 $(135,1 \mathrm{mmHg})$, com média de $105,77 \mathrm{mmHg}$, observa-se inversão dos valores, ou seja, constata-se diminuição considerável na pressão de ruptura entre os grupos GC7 e GJ7.

\section{Conclusão}

Devido à resistência mecânica ter aumentado no GJ no $3^{\circ}$ dia quando comparado ao GC do mesmo dia, sugere-se que existe efeito benéfico da Jatropha neste período. Contudo isto não se mantém em período mais longo de observação dificultando a interpretação de beneficio efetivo da planta. No estudo histológico do processo inflamatório houve pequeno favorecimento para o grupo Jatropha, tanto no terceiro como no sétimo dia indicando ação positiva para a cicatrização.

\section{Referências}

1. Corsi, Rosangely C. Cavanha; Pirana, Sulene; Muraco, Fabio Americo E; Jorge, Douglas. Cicatrização das feridas - Revisão da literatura. Rev Bras Cir. 1994; 84:17-24.

2. Robson MC, Steed DL, Franz MG. Wound healing: Biologic Features and Approaches to Maximize Healing Trajectories. Curr Probl in Surg. 2001; 38:72-140.

3. Seifert WF, Wobbes T, Hendriks T. Divergen patterns of matrix metalloproteinase activity during wound healing in ileum and colon of rats. Gut. 1996;39:114-9.

4. Greca FH, Biondo-Simões MLP, Ioshi S, Santos EAA , Chin EWK, El Tawil II, Stalhschmidt FL. Cicatrização de anastomoses do cólon esquerdo com doença inflamatória. Estudo experimental em ratos. Acta Cir Bras. 2000;15:41-6.

5. Soares EWS, Campos ACL, Matias JEF, Coelho JCU, Malafaia O. Influência da quimioterapia pós-operatória com 5-Fluorouracil na cicatrização de anastomoses colônicas em ratos.ABCD Arq Bras Cir Dig. 2002; 15:31-5.

6. Warde PJ. Estudo Colorretal Experimental em um ou em dois planos de sutura: Estudo Comparativo. São Paulo.[Tese-Doutorado]. São Paulo:Universidade de São Paulo:Faculdade de Medicina; 1972.

7. Nair SK, Bhat IK, Aurora AL. Role of Proteolytic Enzyme in the Prevention of Postoperative Intraperitoneal Adhesions. Arch Surg. 1974; 108:849-53.

8. Paes AMA. Estudo da atividade anti-hipertensiva da Jatropha gossypiifolia L. (pião roxo). São Luís, 1996. [Monografia -Graduação] .São Luís:Universidade Federal do Maranhão:Centro de Ciências Biológicas e da Saúde; 1996. 
9. Abreu CI. Estudo do Mecanismo da Ação Relaxante Vascular do Extrato Etanólico de Jatropha gossypiifolia Linn. (pião roxo) em Artéria Mesentérica de Ratos. [Monografia-Graduação]. São Luis: Universidade Federal do Maranhão, Centro de Ciências Biológicas e da Saúde; 2002.

10. Biondo-Simões MLP, Greca FH, Ioshii SO, Chin EKW, Kimura LY. Colectomia subtotal e anastomose com doença inflamatória residual. Estudo experimental em ratos. Rev Bras Coloproctol. 2002; 22:8-8.

11. Biondo-Simões MLP, Greca FH, Bryk Jr. A, Komatsu MCG, Bittencourt FO, Greca LM. Influência da peritonite sobre a síntese de colágeno em anastomoses do cólon distal - Estudo experimental em ratos. Acta Cir Bras. 2000;15:69-73.

12. Hendriks T, Mastboom WJB. Healing of Experimental Intestinal Anastomoses. Parameters for repair. Dis Colon Rectum.1990; 33:891-901.

13. Verhofstad MH, Lange WP, Laak van der Laak JÁ, Verhofstad AA, Hendriks T. Microscopic Analysis of Anastomotic Healing in the Intestine of normal and diabetic rats. Dis Colon Rectum. 2001; 44:423-31.
14. Leite CVS, Naresse LE, Kobayasi S, Minossi JG, Burini RC, Curi PR, Hossne WS. Efeito da desnutrição protéica na anastomose do cólon distal no rato: estudo da força de ruptura e do colágeno tecidual. Acta Cir Bras. 1993; 8:145-150.

15. Kiyama T, Efron DT, Tantry V, Barbul A. Effect of Nutritional Route on Colonic Anastomotic Healing in the Rat. J Gastrointest Surg. 1999; 3:441-6.

16. García-Olmo D, Paya J, Lucas FJ, García-Olmo DC. The effects of the pharmacological manipulation of postoperative intestinal motility on colonic anastomoses. Int $\mathrm{J}$ Colorectal Dis. 1997; 12: 73-7.

17. Wu FC, Ayrizono MLS, Fagundes JJ, Coy CSR, Góes JRN, Leonardi LS. Estudos biomecânicos de ação de aderências sobre anastomose cólica. Trabalho experimental em ratos. Acta Cir Bras. 2003; 18:216-23.

18. Ramzi S. Robins basis of disease. $6^{\mathrm{a}} \mathrm{ed}$. Philadelphia: WB. Saunders Company; 1999.

19. Robbins S. Patologia estrutural e funcional. $6^{\text {a ed. Rio }}$ de janeiro: Guanabara Koogan, 2000.

\section{Correspondência:}

Conflito de interesses: nenhum Fonte de financiamento: Capes

Recebimento: 21/02/2005

Revisão: 10/06/2005

Aprovação: 15/06/2006

\section{Como citar este artigo:}

Servin SCN, Torres OJM, Matias JEF, Agulham MÂ Carvalho FA, Lemos R, Soares EWS, Soltoski PR, Freitas ACT. Ação do extrato de Jatropha gossypiifolia L. (pião roxo) na cicatrização de anastomose colônica: estudo experimental em ratos. Acta Cir Bras. [periódico na internet] 2006;21 Supl 3:89-96. Disponível em URL: http://www.scielo.br/acb

*Figuras coloridas disponíveis em www.scielo.br/acb 